\title{
Ventilation System Operation to Minimize the COVID-19 Airborne Transmission in Schools
}

\author{
Luca Stabile*, Antonio Pacitto, Giorgio Buonanno, Marco Dell'Isola \\ Department of Civil and Mechanical Engineering, University of Cassino and Southern Lazio, via G. Di Biasio, 43, 03043 \\ Cassino (FR), Italy
}

Corresponding Author Email: 1.stabile@unicas.it

https://doi.org/10.18280/ti-ijes.652-424

Received: 18 March 2021

Accepted: 29 May 2021

\section{Keywords: \\ SARS-CoV-2, schools, ventilation, infection risk assessment, indoor}

\begin{abstract}
Minimizing the SARS-CoV-2 virus transmission is essential to face the COVID-19 pandemic. This is even more important for highly crowded indoor environments, e.g. schools, where the mitigation solutions based on social distancing and hand washing seem to be not effective to reduce the virus airborne transmission mode, which is the main route of transmission. To minimize the airborne virus transmission a proper ventilation is necessary. In the study, a simplified mass balance equation (box-model) was applied to school scenarios in order to determine the required conditions to maintain the infection risk below an acceptable level. In particular, the required air exchange rates for mechanicallyventilated classrooms and the adequate airing procedures for naturally ventilated classrooms were determined. Moreover, for naturally ventilated classrooms, a control strategy based on the measurement of $\mathrm{CO}_{2}$ indoor concentration was also developed.
\end{abstract}

\section{INTRODUCTION}

The worldwide uncontrolled spread of the SARS-CoV-2 virus has put the indoor environments in the spotlight for their significant contribution to the virus transmission $[1,2]$. In fact, indoor environments typically present poor ventilation, also in the case of highly crowded environments (such as schools). This condition does not allow a proper dilution of the virusladen respiratory droplets emitted by an infected subject, leading to high percentages of secondary infections amongst subjects sharing the same confined space $[2,3]$. For this reason, governments worldwide have imposed temporary shutdowns of most of the indoor environments, including schools [4, 5], being in the uncomfortable role of deciding whether prioritising socio-economic development and the right to education or health. After the first pandemic wave, guidelines for reopening schools focus their attention mainly on personal behaviours and basic non-pharmaceutical mitigation measures, as social distancing, hand washing hand, wearing masks. These essential rules can just limit the close contact transmission due to the large droplets, which is (if a social distance is guaranteed) a minor route of transmission in indoor environments $[2,3,6]$. After the first reopening, schools were closed again during fall and winter in many countries worldwide [7], highlighting the limited effect of such measures in the indoor environments. In light of this, it becomes mandatory also consider the airborne transmission route of the virus to open schools safely because it is potentially the dominant mode of transmission of numerous respiratory infections, including SARS-CoV-2 [3, 6, 8]. Hence, while waiting for a massive vaccination campaign, a possible solution to limit the virus transmission potential in schools is providing ad-hoc ventilation rates able to lower the virus concentration indoors $[9,10]$. Nonetheless, it is not an easy solution to provide a proper ventilation rate because most schools worldwide rely upon natural ventilation and manual airing (e.g. almost 90\% of the European schools [11]). For these schools, a good solution could be using a proxy to provide real-time information on the virus concentration in the indoor environment and, consequently, applying manual procedures to control and minimise the virus spread in indoor environments.

Some studies propose the occupants' exhaled $\mathrm{CO}_{2}$ as a possible proxy for virus spreading in an indoor environment [12]. Still, this approach could be considered an oversimplified way to cope with the problem of the virus spread in indoor environments. In fact, the exhaled $\mathrm{CO}_{2}$ could be a good proxy for indoor-generated gaseous pollutants (as VOCs) [13], but it can be hardly adopted to forecast behaviours and dynamics of virus-laden droplets that are affected by phenomena typical of airborne particles as deposition, filtration and virus inactivation (in the case of the virus). On the contrary, thanks to the decay dynamics of the $\mathrm{CO}_{2}$ concentration, the exhaled $\mathrm{CO}_{2}$ can be used to estimate the air exchange rate of indoor environments [14].

At the time of the COVID-19 pandemic, the question is not just demonstrating the qualitative association between ventilation and the transmission of infectious diseases, but quantifying and guaranteeing adequate ventilation in highly crowded environments (e.g. schools) to reduce the virus transmission via airborne route whether mechanical ventilation systems are installed or not.

The present paper aims to evaluate the required air exchange rates for mechanically-ventilated schools and the adequate airing procedures for naturally ventilated schools in order to reduce respiratory disease transmission due to the virus airborne route in classrooms. Moreover, in this study, different mitigation measures (vocal modulation, wear face masks or reduce the lesson time) were also taken into account. To this end, simulations based on virus and exhaled $\mathrm{CO}_{2}$ mass balance equations considering typical school scenarios were carried out. 


\section{METHODOLOGY}

Using the virus and $\mathrm{CO}_{2}$ mass balance equations and under the simplified hypothesis that the concentrations of both $\left(\mathrm{CO}_{2}\right.$ and virus) are instantaneously and evenly distributed in the indoor environment under investigation (box-model), the required air exchange rates and the adequate airing procedures to guarantee an acceptable virus transmission were calculated. In this study, the deposition and the virus inactivation phenomena were taken into account, and dynamic scenarios have been simulated within the 5-hour school day. In this study, the authors considered two different viruses (SARS-CoV-2 and seasonal influenza), characterised by extremely different emission rates (i.e. different viral loads and infectious doses) [15]. The study involves infected people breathing and/or speaking whereas symptomatic persons frequently coughing or sneezing were not included in the scenarios. The simulations were performed under the hypothesis that the students are adequately spaced, and this leads to consider negligible the close contact; thus, the virus transmission is only due to the airborne route which involves people sharing room air and maintaining distancing.

\subsection{Estimation of the virus transmission}

The virus transmission due to the airborne route was evaluated in terms of event reproduction number $\left(\mathrm{R}_{\mathrm{event}}\right)$, adopting the proposed approach in our previous papers [3], [16]. Through this approach, it is possible to evaluate (i) the quanta emission rate, (ii) the exposure to quanta concentration in the microenvironment, (iii) the dose of quanta received by exposed susceptible subjects, (iv) the probability of infection based on a dose-response model, (v) the individual risk of the exposed person, and, finally, (vi) the event reproduction number. In particular, the quanta emission rates $\left(\mathrm{ER}_{\mathrm{q}}\right.$, quanta $\mathrm{h}^{-1}$ ) were evaluated through an ad-hoc model already described in our previous papers; this model takes into account: viral load, infectious dose, respiratory activity, activity level, and droplet volume concentration expelled by the contagious person $[3,15,16]$. Indeed, the "quanta" represents the minimum amount of virions emitted by the infected subject which is able to infect a susceptible person (more precisely, it is defined as the infectious dose for $63 \%$ of susceptibles by inhalation of virus-laden particles).

Such a model, here not reported for the sake of brevity, provides a distribution of quanta emission rates, i.e. the probability density function of $\mathrm{ER}_{\mathrm{q}}$. This approach represents a step forward to simulate and predict infection risk in different indoor environments. The indoor quanta concentration over time, $n\left(t, \mathrm{ER}_{\mathrm{q}}\right)$, is evaluated, for each possible $\mathrm{ER}_{\mathrm{q}}$ value, adopting the above-mentioned simplified mass balance equation:

$$
n\left(t, E R_{q}\right)=E R_{q} \cdot I \cdot \frac{\left(1-e^{-(A E R+k+\lambda) \cdot t}\right)}{(A E R+k+\lambda) \cdot V} \quad\left(\text { quanta } \mathrm{m}^{-3}\right)
$$

where $\operatorname{AER}\left(\mathrm{h}^{-1}\right)$ is the air exchange rate, $\mathrm{k}\left(\mathrm{h}^{-1}\right)$ is the deposition rate on surfaces, $\lambda\left(\mathrm{h}^{-1}\right)$ is the viral inactivation rate, $I$ is the number of infectious subjects, and $\mathrm{V}$ is the volume of the indoor environment.

The dose of quanta $\left(D_{q}\right)$ received by a susceptible subject exposed to a certain quanta concentration for a certain time interval, $T$, can be evaluated by integrating the quanta concentration over time as:

$$
D_{q}\left(E R_{q}\right)=I R \int_{0}^{T} n\left(t, E R_{q}\right) d t \quad \text { (quanta) }
$$

where, IR is the inhalation rate of the exposed subject which is a function of the subject's activity level and age [17].

The probability of infection $\left(\mathrm{P}_{\mathrm{I}}, \%\right)$ of exposed persons (for a certain $E_{\mathrm{q}}$ ), is evaluated on the basis of simple Poisson dose-response model [18] as:

$$
P_{I}\left(E R_{q}\right)=1-e^{-D_{q}\left(E R_{q}\right)}
$$

The individual risk of infection ( $\mathrm{R}$ ) of an exposed person for a given exposure scenario is then calculated integrating, over for all the possible $E_{\mathrm{q}}$ values, the product between the conditional probability of the infection for each $\operatorname{ER}_{\mathrm{q}}\left(\mathrm{P}_{\mathrm{I}}\left(\mathrm{ER}_{\mathrm{q}}\right)\right)$ and the probability of occurrence of each $E_{\mathrm{q}}$ value $\left(\mathrm{P}_{\mathrm{ERq}}\right)$ :

$$
R=\int_{E R_{q}}\left(P_{I}\left(E R_{q}\right) \cdot P_{E R q}\right) d E R_{q} \quad(\%)
$$

Such an individual risk $\mathrm{R}$, for a given exposure scenario, basically represents the ratio between the number of new infections (number of cases, C) and the number of exposed susceptible individuals ( $\mathrm{S}$ ); thus, the $\mathrm{R}_{\text {event }}$ (expected number of new infections, $\mathrm{C}$, arising from a single infectious individual, $I$, at a specific event) can be obtained as the product of $\mathrm{R}$ and $\mathrm{S}$ :

$$
R_{\text {event }}=C / I=R \cdot S \quad \text { (infections) }
$$

Therefore, the maximum number of susceptibles that can stay simultaneously in the confined space under investigation for an acceptable $\mathrm{R}_{\text {event }}<1$ (hereinafter referred as maximum room occupancy, MRO) is:

$$
\mathrm{MRO}<1 / R \quad \text { (susceptibles) }
$$

\subsection{Evaluation of the $\mathrm{CO}_{2}$ indoor levels}

To estimate the trend of indoor (exhaled) $\mathrm{CO}_{2}$ concentration over time $\left(\mathrm{CO}_{2 \text {-in }}\right)$, a mass balance equation was applied as well; in particular, considering the initial indoor $\mathrm{CO}_{2}$ concentration (at $t=0$ ) equals to the outdoor one $\left(\mathrm{CO}_{2 \text {-out }}\right)$, the mass balance equation can be simplified as [14]:

$$
C O_{2-i n}(t)=C O_{2-o u t}+E R \cdot \frac{\left(1-e^{-A E R \cdot t}\right)}{V \cdot A E R} \quad(\mathrm{ppm})
$$

ER represents the overall exhaled $\mathrm{CO}_{2}$ emission rate in the indoor environment under investigation; the emission rate percapita is available in the scientific literature (typically expressed in $\mathrm{L} \mathrm{s}^{-1}$ person ${ }^{-1}$ ) as a function of the activity level age, gender [19]. As mentioned above, for known and steadystate emission rate and outdoor $\mathrm{CO}_{2}$ concentration, the indoor concentration is just affected by the air exchange rate of the room, and the AER can be back-calculated from the Eq. (7) measuring continuously the indoor $\mathrm{CO}_{2}$ concentration $\left(\mathrm{CO}_{2 \text {-in }}\right)$ : this measurement method is known as "constant injection rate method".

\subsection{Simulated scenarios}

The $\mathrm{R}_{\text {event }}$ and the individual risk of infection related to the virus airborne transmission route were evaluated considering a high-school classroom with a floor area of $50 \mathrm{~m}^{2}$ and a height 
of $3 \mathrm{~m}$. A crowding index equal to $2 \mathrm{~m}^{2}$ person $^{-1}$ was adopted, leading to a total number of occupants (including the teacher) equal to 25 persons [20]. For the simulations a school time of 5 hours was considered. All the simulations were performed considering only one infected subject $(I=1)$ (the teacher or one of the students) and 24 exposed susceptibles $(S=24)$, hypothesising that none of them is already immune. In light of this, to obtain a $\mathrm{R}_{\text {event }}<1$, the individual risk of infection (R) of the exposed susceptible over the 5-hour school time should be less than $4.2 \%$. The simulations were conducted for different scenarios, considering two different emitting subjects: the teacher and the student. In particular, simulations were performed considering (a) the infected teacher giving lesson (i.e. speaking or loudly speaking) for one hour, specifically, the first hour of the school day was considered as it is the worst exposure scenario for susceptible students attending the lesson, or (b) the infected student attending lessons (just breathing). Details of the scenarios are summarised in Table 1. As regards the susceptibles, an IR $=0.54 \mathrm{~m}^{3} \mathrm{~h}^{-1}$, characteristic of people performing activities in a sitting position, was adopted [17]. The quanta emission rate for SARS-CoV-2 and seasonal influenza viruses, as a function of respiratory activity, virus inactivation rate and droplet deposition rate, are summarised in Table 2 [3]. For both viruses, the $\mathrm{ER}_{\mathrm{q}}$ increases for more severe respiratory activities; besides, due to its higher infectious dose, for similar activity levels and respiratory activities, the SARS-CoV-2 ER values were much higher than the seasonal influenza ones $[15,21,22]$ (e.g. more than 10fold). As regards the vocal modulation (e.g. using microphones) $\mathrm{ER}_{\mathrm{q}}$ values for speaking persons were considered (scenario T-60-S), whereas, when simulating scenarios considering mask use, an overall $40 \%$ reduction of the dose of quanta received by the susceptible (scenario T-60LS-M) was adopted. In the simulations of the $\mathrm{CO}_{2}$ concentrations an outdoor $\mathrm{CO}_{2}$ equal to 500 ppm was adopted. Instead, for indoor (exhaled) $\mathrm{CO}_{2}$ was used an emission rate considering a per-capita emission rate equal to $0.0044 \mathrm{~L} \mathrm{~s}^{-1}$ person $^{-1}$ as an average value between male and female teenager students (e.g. aged 17-18) with a level of physical activity of 1.3 met [19], which is the suggested level for reading, writing, typing in sitting position at school.

Table 1. Scenarios considered to simulate the exposure to SARS-CoV-2 and seasonal influenza viruses in the classroom

\begin{tabular}{cccc}
\hline Scenarios & & Emitting subject & Emission duration (min), respiratory activity \\
\hline Base scenarios & T-60-LS & teacher & 60 min, loudly speaking \\
Voice modulation effect & S-0\%-S & student & 300 min, oral breathing \\
Mask effect & T-60-S & teacher & 60 min, speaking \\
Voice modulation \& mask effect & T-60-LS-M & teacher & 60 min, loudly speaking \\
\hline
\end{tabular}

Table 2. Quanta emission rate $\left(\mathrm{ER}_{\mathrm{q}}\right.$, quanta $\left.\mathrm{h}^{-1}\right)$, expressed as $\log _{10}$ average and standard deviation values, for $\mathrm{SARS}-\mathrm{CoV}-2$ and Seasonal Influenza viruses as a function of respiratory activity. Virus inactivation rate, $\lambda\left(\mathrm{h}^{-1}\right)$, and droplet deposition rate, $\mathrm{k}\left(\mathrm{h}^{-1}\right)$ are also reported

\begin{tabular}{llll}
\hline & & SARS-CoV-2 & Seasonal Influenza \\
\hline \multirow{2}{*}{ Oral breathing } & $\log _{10}$ average & -0.24 & -1.40 \\
& $\log _{10}$ st. dev. & 1.20 & 0.84 \\
Speaking & $\log _{10}$ average & 0.41 & -0.77 \\
& $\log _{10}$ st. dev. & 1.20 & 0.84 \\
Loudly speaking & $\log _{10}$ average & 1.20 & 0.06 \\
$\lambda\left(\mathrm{h}^{-1}\right)$ & $\log _{10}$ st. dev. & 1.20 & 0.44 \\
$\mathrm{k}\left(\mathrm{h}^{-1}\right)$ & & 0.63 & 0.80 \\
\hline
\end{tabular}

\subsection{Air exchange rates and airing procedures}

Following the methodology described in the previous sections, especially the eq. 1-5, the required air exchange rate to guarantee a $R_{\text {event }}<1$ can be obtained. In fact, knowing (i) the quanta emission rate related to the activity of the emission subject, (ii) the geometry of the classroom, (iii) the virus inactivation rate $(\lambda)$ for SARS-CoV-2 $\left(0.63 \mathrm{~h}^{-1}\right)$ [23] and seasonal influenza $\left(0.80 \mathrm{~h}^{-1}\right)$ [24] as well as (iv) the droplet deposition rate $\left(\mathrm{k}=0.24 \mathrm{~h}^{-1}\right)$ [25], the individual risk of infection (R) and, consequently, the event reproduction number, depends just by the air exchange rate and the airing procedure of the classroom.

An effective ventilation technique is represented by mechanical ventilation since a required ventilation rate can be easily obtained just by setting a fixed airflow rate. Thus, the required air exchange rate is guaranteed by default. The majority of the schools are not equipped with a mechanical ventilation system. For this reason, to guarantee a $R_{\text {event }}<1$ adhoc manual airing procedures based on manual airing cycles are needed. Indeed, unlike mechanical ventilation systems, which can provide a constant air exchange rate (AER), the manual airing cycles will alternate periods at low AER (with window close) and periods at higher AER (with the window open). One of the most critical points is represented by the fact that such air exchange rates are not known a-priori. Thus, in naturally-ventilated schools, the required AER cannot be defined and adopted as a design parameter. The air exchange rate of the manual airing procedure can just be calculated aposteriori as school-day average resulting from the airing cycles:

$$
A E R=\frac{\left(A E R_{N V} \cdot t_{N V}+A E R_{M A} \cdot t_{M A}\right)}{\left(t_{N V}+t_{M A}\right)}
$$

$\mathrm{AER}_{\mathrm{NV}}$ and $\mathrm{AER}_{\mathrm{MA}}$ represent the air exchange rates with window close (natural ventilation, $\mathrm{NV}$ ) and window open (manual airing, $\mathrm{MA}$ ), and $\mathrm{t}_{\mathrm{NV}}$ and $\mathrm{t}_{\mathrm{MA}}$ are the time during which the windows were kept closed and open. Since the air exchange rate is not constant all over the school day, the time at which the airing is adopted can affect the quanta 
concentration trends significantly. In fact, when windows are closed and a high quanta emission occurs, the susceptibles are exposed to higher quanta concentrations then leading to a dose of quanta larger than expected for a constant air exchange rate; consequently, susceptibles can present a higher infection risk. For this reason, in the case of manual airing, it is necessary to provide higher AER to guarantee a $R_{\text {event }}<1$ concerning classrooms equipped with mechanical ventilation systems, especially when the virus emission is high and quick. In this study, the manual airing cycles were applied at the end of each school hour.

Moreover, as mentioned above, not knowing the exact AER can lead to $\mathrm{R}_{\text {event }}>1$. To avoid this happen feedback information is necessary; to this end, in this paper, a proper feedback control strategy to correct the airing procedure was proposed and applied as reported in the result section.

\section{RESULTS}

Trends of quanta concentration, individual risk, Maximum Room Occupancy, and indoor $\mathrm{CO}_{2}$ concentration are reported for the scenarios T-60-LS (teacher giving lesson loudly speaking for the first 60 min of the school day) and T-60-S (i.e. speaking using a microphone instead of loudly speaking) are reported in Figure 1 in the case of SARS-CoV-2 virus when required AERs are adopted (to guarantee a $R_{\text {event }}<1$ ). Such examples are representative of a school equipped with a mechanical ventilation system hypothesizing a perfect (homogeneous) air distribution in the room. In particular, for the scenario T-60-LS, as summarized in Table 3, the required AER is $9.5 \mathrm{~h}^{-1}$ (i.e. $>15 \mathrm{~L} \mathrm{~s}^{-1}$ person ${ }^{-1}$ ). As shown in Figure 1, the quanta concentration trend increases in the first $60 \mathrm{~min}$ (the time in which the infected subject is still in the classroom), then quickly decays as soon as the teacher leaves the room and goes to zero at about $90 \mathrm{~min}$. The individual risk increases reaching the maximum permitted value $(4.2 \%)$ already at 90 min, then remaining constant up to the end of the school day (300 $\mathrm{min}$ ), under the condition that no one infected subject enter the classroom.

Regarding the maximum occupancy, that values decreases to the needed value of 24 persons at the end of the school day. As regards $\mathrm{CO}_{2}$ concentration in the classroom, due to the high (and constant) $\mathrm{AER}=9.5 \mathrm{~h}^{-1}$, the $\mathrm{CO}_{2}$ indoor reaches the (very low) equilibrium concentration (about $750 \mathrm{ppm}$ ) in about half an hour. In the case of scenario T-60-S, a much lower AER $\left(0.8 \mathrm{~h}^{-1}\right.$; equal to $1.3 \mathrm{~L} \mathrm{~s}^{-1}$ person $\left.{ }^{-1}\right)$ is required to guarantee a $\mathrm{R}_{\text {event }}<1$, indeed, the $\mathrm{CO}_{2}$ indoor concentration does not even reach an equilibrium level and continuously increases up to more than $3000 \mathrm{ppm}$ in overall school-day, and such a value is well above the concentrations suggested by the indoor air quality standards [20]. The AERs needed to guarantee a $R_{\text {event }}$ $<1$ for all the investigated scenarios are reported in Table 3 for SARS-CoV-2 (for mechanically-ventilated classrooms). As regards the required AER for seasonal influenza-infected subjects is not reported since it is $<0.1 \mathrm{~h}^{-1}$ for all the scenarios under investigation.

For this reason, all the ventilation techniques can protect against the spreading of the seasonal influenza virus in the classroom. Instead, for SARS-CoV-2-infected subjects, the AERs to guarantee a $\mathrm{R}_{\text {event }}<1$ can be quite high: as mentioned above, for a teacher giving a lesson for one hour, the required AER is $9.5 \mathrm{~h}^{-1}$. It is possible to reduce such AERs keeping the voice down while speaking using microphones, and this adoption could reduce the required AERs until $0.8 \mathrm{~h}^{-1}$. In the case of the infected subject being a student, and he does not speak for the entire school day, the required AER to guarantee a $R_{\text {event }}<1$ is equal to $0.8 \mathrm{~h}^{-1}$.

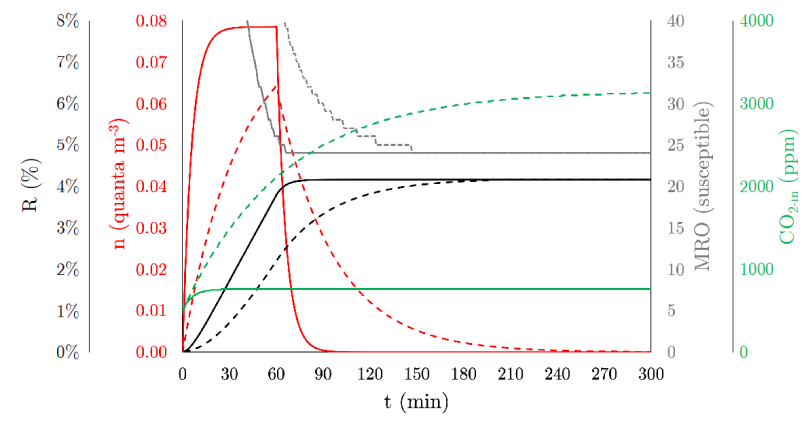

Figure 1. Trends of quanta concentration $(n)$, individual risk (R), Maximum Room Occupancy (MRO), and indoor $\mathrm{CO}_{2}$ concentration $\left(\mathrm{CO}_{2 \text {-in }}\right)$ resulting from the simulation of the base scenarios T-60-LS (solid lines) and T-60-S (dotted lines) in the case of SARS-CoV-2 virus having adopted the required constant AERs to guarantee a $\mathrm{R}_{\text {event }}<1\left(9.5 \mathrm{~h}^{-1}\right.$ and $0.8 \mathrm{~h}^{-1}$ for T-60-LS and T-60-S, respectively) through a mechanical ventilation system.

Table 3. Required constant AER $\left(\mathrm{h}^{-1}\right)$ to guarantee a $\mathrm{R}_{\text {event }}<$ 1 for all the scenarios investigated for SARS-CoV-2 for mechanically-ventilated classrooms

\begin{tabular}{ccc}
\hline Scenarios & & AER $\left(\mathrm{h}^{-1}\right)$ \\
\hline Base scenarios & T-60-LS & 9.5 \\
Voice modulation effect & S-0\%-S & 0.8 \\
Mask effect & T-60-S & 0.8 \\
T-60-LS-M & 5.8 \\
Voice modulation \& mask effect & T-60-S-M & 0.2 \\
\hline
\end{tabular}

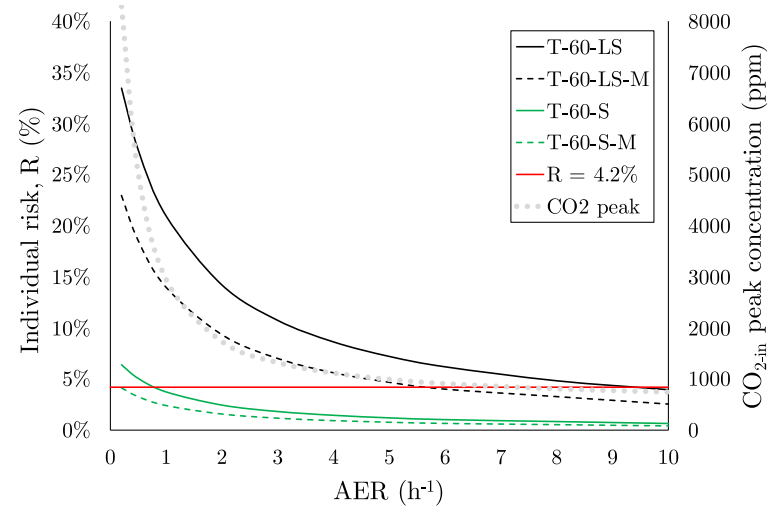

Figure 2. Individual risk R (\%), for different exposure scenarios in the case of a SARS-CoV-2 infected teacher giving lesson for $60 \mathrm{~min}$ as a function of the air exchange rate in mechanically-ventilated classrooms: loudly speaking (T-60-LS), speaking (T-60-S), loudly speaking and wearing a mask (T-60-LS-M). In addition, expected $\mathrm{CO}_{2}$ peak concentrations (i.e. at the end of the school day) as a function of the AERs are also reported

For different scenarios in the case of the SARS-CoV-2infected teacher (giving lesson for $60 \mathrm{~min}$ ) as a function of the air exchange rate in a classroom equipped with a mechanical ventilation system, the individual risk $\mathrm{R}$ is showed in Figure 2 for the scenarios T-60-LS (teacher loudly speaking) and the mitigation solutions T-60-S and T-60-LS-M (voice 
modulation and use of mask). The individual risk decreases for higher AERs and, as showed in Table 3, very high AERs are required when the teacher is loudly speaking. Likely these values of AERs are not reproducible in school without mechanical ventilation systems.

In Figure 2, the expected $\mathrm{CO}_{2}$ peak concentrations at the end of the school day as a function of the AERs are also reported. The graph shows that the $\mathrm{CO}_{2}$ level could be misleading when not interpreted with a critical eye; in fact, even if acceptable $\mathrm{CO}_{2}$ levels are guaranteed (e.g. $1000 \mathrm{ppm}$ ), a not acceptable individual risk can occur. In light of this, for high-emitting activities (i.e. loudly speaking), the mitigation solutions (e.g. using a microphone) are more effective than the classroom ventilation itself.

As previously mentioned in the methodology section, in mechanically-ventilated classrooms, the $R_{\text {event }}<1$ condition is easily and automatically guaranteed if the required AERs obtained for the selected scenarios are adopted. In that case, a simple constant air volume flow system is enough to supply the necessary AER, and no complex control algorithms are needed. Once we defined the scenario, applying the methodology previously described, we know the required AER to guarantee the $\mathrm{R}_{\text {event }}<1$. At this point, it is necessary just to set the needed airflow rate of the mechanical ventilation system.

Differently, for schools without mechanical ventilation, guaranteeing a $\mathrm{R}_{\text {event }}<1$ could be challenging, especially for scenarios characterised by high emitting infected subjects for two main reasons: i) keeping the windows opened could be not enough to guarantee very high fresh air flow rates, ii) keeping the windows opened for long periods could be detrimental from thermal comfort and energy-saving point of views. Nonetheless, in the case of less critical scenarios, the adoption of manual airing cycles could represent a practical solution. Still, it should be kept in mind that (i) the scheduling of window opening and closing period can affect the infection risk of the exposed susceptibles and (ii) the required AER cannot be determined a-priori. For example, if $\mathrm{AER}_{\mathrm{NV}}$ and $\mathrm{AER}_{\mathrm{MA}}$ were equal (and constant) to 0.2 and $4.0 \mathrm{~h}^{-1}$, respectively, for the scenario T-60-S, a $\mathrm{R}_{\text {event }}<1$ could be achievable by opening the windows for about $10 \mathrm{~min}$ each hour. The resulting school day average AER would be equal to $0.8 \mathrm{~h}^{-1}$, which is similar to that needed in the case of mechanical ventilation systems. But for lower AERs, $\mathrm{AER}_{\mathrm{NV}}=0.15$ and $\mathrm{AER}_{\mathrm{MA}}=0.2 \mathrm{~h}^{-1}$, the required opening period for each hour is $36 \mathrm{~min}$ then resulting in a school-day average AER of $1.3 \mathrm{~h}^{-1}$ that is significantly higher than that required in the case of the mechanical ventilation system $\left(0.8 \mathrm{~h}^{-1}\right)$. Thus, the airing strategies are strongly affected by the air exchange rate values; therefore, $A E R_{N V}$ and $A_{E R} R_{M A}$ need to be continuously monitored and corrected. Therefore, the naturally-ventilated school procedure is more complex with respect to the mechanically-ventilated ones. In this study, we will use as feedback information the indoor $\mathrm{CO}_{2}$ concentration continuously measured and, based on the number of persons and their activity levels and of the initial indoor $\mathrm{CO}_{2}$ concentration, we will back-calculate the actual AERs during both the period with windows close $\left(\mathrm{AER}_{\mathrm{NV}}\right)$ and open (AER $\mathrm{AA}_{\mathrm{MA}}$ ) using the $\mathrm{CO}_{2}$ mass balance equation (Eq. 7). Based on the actual AERs, the corrected $t_{\mathrm{MA}}$ and $t_{\mathrm{NV}}$ periods will be calculated and scheduled to obtain a $R_{\text {event }}<1$. Since the $\mathrm{AER}_{\mathrm{NV}}$ and $A E R_{\mathrm{MA}}$ values are not known a-priori, during the first hour/cycle, it is possible to use tentative opening and closing periods (for example, 50 min with windows closed and
10 min with windows open). Then, the evaluation of the actual AERs will allow scheduling the equally-spaced opening periods of the remaining four hours to obtain a $R_{\text {event }}<1$ including the entire school day (i.e. 300 minutes) in the calculation. At the end of the second cycle, $\mathrm{AER}_{\mathrm{NV}}$ and $\mathrm{AER}_{\mathrm{MA}}$ will be back-calculated again, and in case, the opening and closing periods will be modified again. To better explain the procedure in Figure 3 is shown a scheme step by step of the entire procedure to be applied to maintain $\mathrm{R}_{\text {event }}<1$

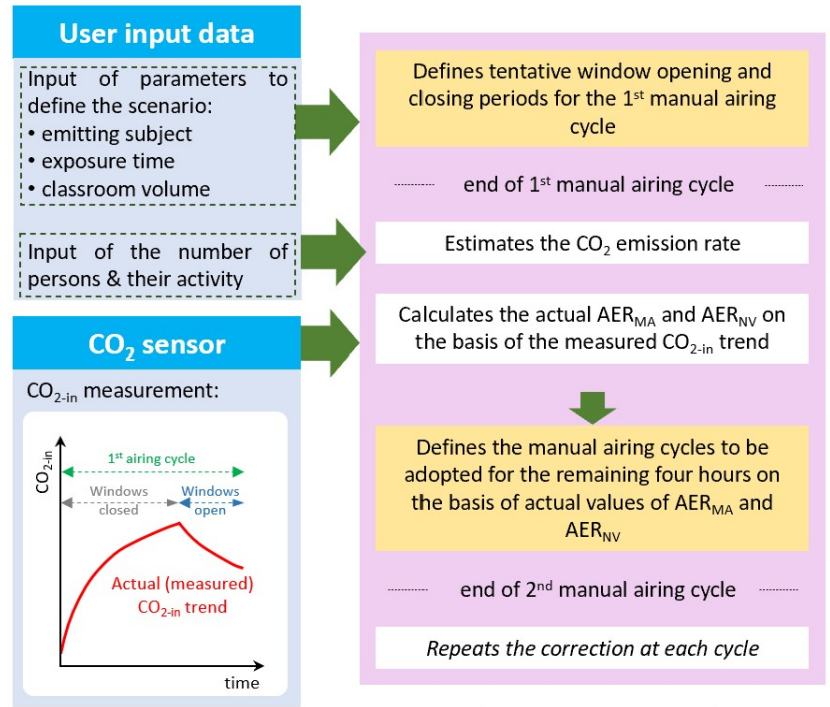

Figure 3. Scheme of the suggested procedures to be applied in schools with and without mechanical ventilation to maintain $R_{\text {event }}<1$

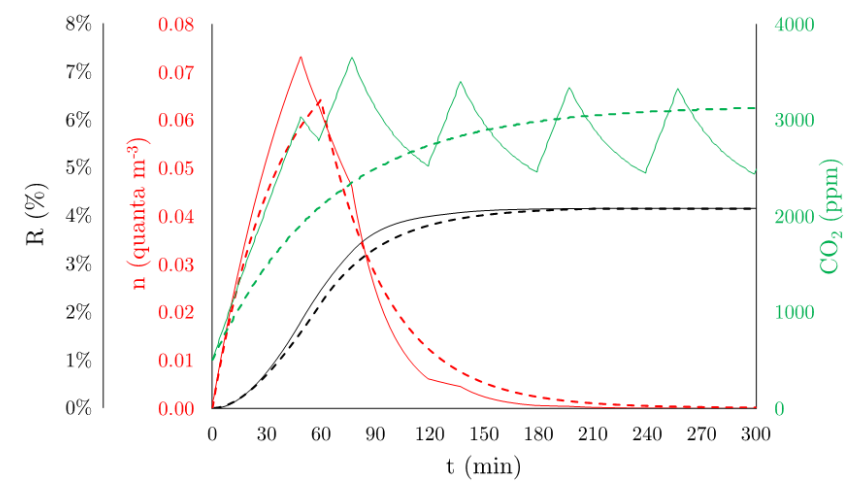

Figure 4. Trends of quanta concentration $(n)$, individual risk $(\mathrm{R})$, and indoor $\mathrm{CO}_{2}$ concentration $\left(\mathrm{CO}_{2}\right.$-in $)$ for the scenario $\mathrm{T}-60-\mathrm{S}$ in the case of SARS-CoV-2 to guarantee a $\mathrm{R}_{\text {event }}<1$ through (a) mechanical ventilation system (constant AER = $0.8 \mathrm{~h}^{-1}$; bold dotted lines) and (b) manual airing procedures corrected for actual AER (school-day average AER $=1.3 \mathrm{~h}^{-1}$ in the hypothesis of measured $\mathrm{AER}_{\mathrm{NV}}$ and $\mathrm{AER}_{\mathrm{MA}}$ of 0.15 and $2.0 \mathrm{~h}^{-1}$, respectively; thin solid lines)

Figure 4 shows an example of the application of the correction procedure in scenario T-60-S, and the indoor $\mathrm{CO}_{2}$ concentration, SARS-CoV-2 quanta concentration, and individual risk trend are reported. In the first hour, a tentative airing cycle of $50 \mathrm{~min}$ with windows closed and $10 \mathrm{~min}$ with windows open was adopted. From the $\mathrm{CO}_{2}$ trend (related to the first cycle), the actual $\mathrm{AER}_{\mathrm{NV}}$ and $\mathrm{AER}_{\mathrm{MA}}$ values were backcalculated and (in this illustrative example) resulted equal to $0.15\left(\mathrm{AER}_{\mathrm{NV}}\right)$ and $2.0\left(\mathrm{AER}_{\mathrm{MA}}\right) \mathrm{h}^{-1}$. Based on the actual AERs (back-calculated), in order to guarantee a $\mathrm{R}_{\text {event }}<1$, a new 
value of $\mathrm{t}_{\mathrm{MA}}$ equally-spaced of $42 \mathrm{~min}$ for each hour for the remaining four hours is applied. Due to this, the total times during which the windows were kept closed and opened for the entire school day are $t_{\mathrm{NV}}=122 \mathrm{~min}$ and $\mathrm{t}_{\mathrm{MA}}=178 \mathrm{~min}$ (including the $50 \mathrm{~min}$ and $10 \mathrm{~min}$ of window closing and opening periods related to the first hour). These new opening periods then result in a school-day average AER of about 1.3 $\mathrm{h}^{-1}$. In light of this, the tentative opening and closing periods adopted for the first hour were too short compared to the effective low AERs. For this reason, the quanta concentration in the first hour increases significantly. In the example, the actual AERs were considered constant during the entire school day; however, if the AERs at the end of each closing and opening periods do no match with the expected ones, further corrections are needed for each hour.

The procedure presented evaluates the required ventilation (using mechanical systems or manual airing) to reduce the spread of infectious diseases via the airborne route and proposed a control strategy to monitor and adjust such ventilation in naturally ventilated classrooms.

\section{CONCLUSIONS}

The study was carried out with the aim to develop procedures able to support regulatory authorities in view of safely running schools at the time of pandemics. The required ventilation to reduce the spread of infectious diseases via the airborne route was assessed for both mechanically and naturally-ventilated classrooms through virus mass balance equations. It was also investigated the possibility to use $\mathrm{CO}_{2}$ concentration as a proxy of a possible exceed of a $\mathrm{R}_{\text {event }}<1$. As a result of the simulated scenarios emerge that adopting a $\mathrm{CO}_{2}$ indoor concentration as a proxy for virus transmission is a misrepresentation; in fact, the dynamics of the virus-laden droplets and the occurrence of the virus emission may strongly differ from the exhaled $\mathrm{CO}_{2}$ ones; due to this, $\mathrm{CO}_{2}$ and virus concentrations present significantly different trends. Regarding seasonal influenza, due to the low emission rates typical of such virus, a negligible transmission potential via the airborne route in the classroom was found, even if it is in the presence of a low air exchange rate. Instead, as regard SARS-CoV-2 virus, the required air exchange rates to guarantee a $\mathrm{R}_{\text {event }}<1$ can be very high for scenarios characterised by highly-emitting infected subjects, such as teacher giving lesson loudly speaking. These AERs may be even higher than those suggested by the indoor air quality technical standards; due to this, mitigation solutions (for example, voice modulation in particular) are welcomed. To reduce the virus transmission, ad-hoc procedures were defined in both mechanically- and naturally-ventilated classrooms. An easy procedure was described regarding mechanicallyventilated classrooms since, once defined the scenario and calculated the required AER to guarantee a $R_{\text {event }}<1$, it barely means setting the necessary AER in the mechanical ventilation system.

On the contrary, in naturally-ventilated classrooms, a suitable feedback control strategy was proposed and applied. In fact, in these classrooms, the required air exchange rate cannot be defined a-priori, and the condition of $R_{\text {event }}<1$ becomes a design parameter. Besides, it is necessary to use $\mathrm{CO}_{2}$ indoor concentration as feedback to check the correct procedure and/or, in case, calculate the new AERs and the new time of windows opening that are necessary to guarantee the condition $\mathrm{R}_{\text {event }}<1$. The authors believe that the suggested procedures can be adopted to minimise the contribution of school environments to the spread of pandemics.

\section{REFERENCES}

[1] Li, Y. (2021). Basic routes of transmission of respiratory pathogens - a new proposal for transmission categorization based on respiratory spray, inhalation, and touch. Indoor Air, 31(1): 3-6. https://doi.org/10.1111/ina.12786

[2] Li, Y. (2021). The respiratory infection inhalation route continuum. Indoor Air, 31(2): 279-281. https://doi.org/10.1111/ina.12806

[3] Buonanno, G., Morawska, L., Stabile, L. (2020). Quantitative assessment of the risk of airborne transmission of SARS-CoV-2 infection: prospective and retrospective applications. Environment International, 145:

106112. https://doi.org/10.1016/j.envint.2020.106112

[4] Petretto, D.R., Masala, I., Masala, C. (2020). School closure and children in the outbreak of COVID-19. Clinical Practice and Epidemiology in Mental Health: CP \& $\quad$ EMH, $16: 189$. https://doi.org/10.2174/1745017902016010189

[5] Farsalinos, K., Poulas, K., Kouretas, D., Vantarakis, A., Leotsinidis, M., Kouvelas, D. (2021). Improved strategies to counter the COVID-19 pandemic: Lockdowns vs. primary and community healthcare. Toxicology Reports, 8: 1-9. https://doi.org/10.1016/j.toxrep.2020.12.001

[6] Morawska, L., Cao, J. (2020). Airborne transmission of SARS-CoV-2: The world should face the reality. Environment International, 139: 105730. https://doi.org/10.1016/j.envint.2020.105730

[7] Edmunds, W.J. (2020). Finding a path to reopen schools during the COVID-19 pandemic. The Lancet Child \& Adolescent Health, 4(11): 796-797. https://doi.org/10.1016/S2352-4642(20)30249-2

[8] Tang, S., Mao, Y., Jones, R.M., Tan, Q., Ji, J.S., Li, N. (2020). Aerosol transmission of SARS-CoV-2? Evidence, prevention and control. Environment International, 144 : 106039. https://doi.org/10.1016/j.envint.2020.106039

[9] Rudnick, S.N., Milton, D.K. (2003). Risk of indoor airborne infection transmission estimated from carbon dioxide concentration. Indoor Air, 13(3): 237-245. https://doi.org/10.1034/j.1600-0668.2003.00189.x

[10] Miller, S.L., Nazaroff, W.W., Jimenez, J.L., Boerstra, A., Buonanno, G., Dancer, S.J. (2021). Transmission of SARS-CoV-2 by inhalation of respiratory aerosol in the Skagit Valley Chorale superspreading event. Indoor Air, 31(2): 314-323. https://doi.org/10.1111/ina.12751

[11] Baloch, R.M., Maesano, C.N., Christoffersen, J., Banerjee, S., Gabriel, M., Csobod, É. (2020). Indoor air pollution, physical and comfort parameters related to schoolchildren's health: Data from the European SINPHONIE study. Science of the Total Environment, 739:

139870 . https://doi.org/10.1016/j.scitotenv.2020.139870

[12] Pavilonis, B., Ierardi, A.M., Levine, L., Mirer, F., Kelvin, E.A. (2021). Estimating aerosol transmission risk of SARS-CoV-2 in New York City public schools during 
reopening. Environmental Research, 195: 110805. https://doi.org/10.1016/j.envres.2021.110805

[13] Stabile, L., Buonanno, G., Frattolillo, A., Dell'Isola, M. (2019). The effect of the ventilation retrofit in a school on $\mathrm{CO}_{2}$, airborne particles, and energy consumptions. Building and Environment, 156: 1-11. https://doi.org/10.1016/j.buildenv.2019.04.001

[14] Mahyuddin, N., Awbi, H. (2012). A review of $\mathrm{CO}_{2}$ measurement procedures in ventilation research. International Journal of Ventilation, 10(4): 353-370. https://doi.org/10.5555/2044-4044-10.4.353

[15] Mikszewski, A., Stabile, L., Buonanno, G., Morawska, L. (2021). The airborne contagiousness of respiratory viruses: A comparative analysis and implications for mitigation.

MedRxiv. https://doi.org/10.1101/2021.01.26.21250580

[16] Buonanno, G., Stabile, L., Morawska, L. (2020). Estimation of airborne viral emission: Quanta emission rate of SARS-CoV-2 for infection risk assessment. Environment International, 141: 105794. https://doi.org/10.1016/j.envint.2020.105794

[17] Adams, W.C., Webb, P.A. (1993). Measurement of breathing rate and volume in routinely performed daily activities. Final Report. Human Performance Laboratory, Physical Education Department, University of California, Davis. Human Performance Laboratory, Physical Education Department, University of California, Davis. Prepared for the California Air Resources Board, Contract, A033-205.

[18] Sze To, G.N., Chao, C.Y.H. (2010). Review and comparison between the Wells-Riley and dose-response approaches to risk assessment of infectious respiratory diseases. Indoor Air, 20(1): 2-16. https://doi.org/10.1111/j.1600-0668.2009.00621.x

[19] Persily, A., de Jonge, L. (2017). Carbon dioxide generation rates for building occupants. Indoor Air, 27(5): 868-879. https://doi.org/10.1111/ina.12383

[20] Comite'Europe'en de Normalisation, C.E.N. (2007). Indoor environmental input parameters for design and assessment of energy performance of buildings addressing indoor air quality, thermal environment, lighting and acoustics. EN 15251.

[21] Gale, P. (2020). Thermodynamic equilibrium doseresponse models for MERS-CoV infection reveal a potential protective role of human lung mucus but not for SARS-CoV-2. Microbial Risk Analysis, 16: 100140. https://doi.org/10.1016/j.mran.2020.100140

[22] Bueno de Mesquita, P.J., Noakes, C.J., Milton, D.K. (2020). Quantitative aerobiologic analysis of an influenza human challenge-transmission trial. Indoor Air, 30(6): 1189-1198. https://doi.org/10.1111/ina.12701

[23] Van Doremalen, N., Bushmaker, T., Morris, D.H., Holbrook, M.G., Gamble, A., Williamson, B.N. (2020). Aerosol and surface stability of SARS-CoV-2 as compared with SARS-CoV-1. New England Journal of Medicine, 382(16): 1564-1567. https://doi.org/10.1056/NEJMc2004973

[24] Yang, W., Marr, L.C. (2011). Dynamics of airborne influenza A viruses indoors and dependence on humidity. PloS One, 6(6): e21481. https://doi.org/10.1371/journal.pone.0021481

[25] Chatoutsidou, S.E., Lazaridis, M. (2019). Assessment of the impact of particulate dry deposition on soiling of indoor cultural heritage objects found in churches and museums/libraries. Journal of Cultural Heritage, 39: 221 228. https://doi.org/10.1016/j.culher.2019.02.017 